\title{
Gastric Outlet Obstruction by Trichobezoar, A Case Report
}

\author{
Akhter SMQ ${ }^{1}$, Reza SM², Ahmad S ${ }^{3}$, Lima IJ ${ }^{4}$, Sony FC ${ }^{5}$, Gupta AS ${ }^{6}$, Islam MS
}

\begin{abstract}
:
Conflict of Interest: None

Received: $27-09-2017$

Accepted: $12-11-2017$

www.banglajol.info/index.php/JSSMC

A trichobezoar is a bezoar ( a mass found tapped in the gastrointestinal system) formed from the ingestion of hair. Trichobezoars are often associated with trichotillomania (compulsive hair pulling). Trichobezoars are rare, but can be fatal if undected ${ }^{1,2}$. Surgical intervention is often required. Gastric outlet obstruction (G.O.O) is one of the presenting complaints of trichobezoars in the stomach. Patients with this condition often have an underlying psychiatric illness \& history may not be easily forthcoming. This condition mainly occurs in young female. We are presenting a case of gastric outlet obstruction in a young female of 25 years old. After taking history, clinical examination, necessary investigation it seemed to be a case of trichobezoar.

Key Words:

G.O.O., Trichobezoar, Laparatomy done under general anaesthesia, then opened the stomach and found it was a case of trichobezoar.
\end{abstract}

Trichotillomania, Trichophagia

[J Shaheed Suhrawardy Med Coll 2017; 9(2): 85-87] DOI: http://dx.doi.org/10.3329/jssmc.v9i2.37270

\section{Introduction:}

A bezoar is a mass of undigested material within the gastro intestinal tract (GIT). The term bezoar derives from Arabic word Badzehar, which means antidote. Trichobezoar is from Greek word which means hair. A trichobezoar is a mass of undigested hair within the GIT. ${ }^{1,2}$ Trichobezoar is often associated with trichotillomania (hair pulling) ${ }^{3} \&$ trichophagia (hair swallowing) Trichotillomania may be unconsciously or unintentionally done \& is part of the DSM IV psychiatric classification of impulse control disorders. In upto $18 \%$ of patients with trichotillomania, trichophagia occurs. ${ }^{4}$ One third of patients with trichophagia develop trichobezoars. Trichobezoars most commonly occur in adolescent females. The site of hair pulling is most commonly from the scalp, but can occur from the eyelashes, eyebrows $\&$ pubic area. ${ }^{4}$

1. Dr. S.M. Quamrul Akhter, Associate Professor of Surgery, ShSMCH, Dhaka.

2. Dr. Syed Masud Reza, Associate Professor of Surgery, ShSMCH, Dhaka.

3. Dr. Sami Ahmad, Associate Professor of Surgery,ShSMCH, Dhaka

4. Dr. Ismat Jahan Lima, Junior Consultant Surgery, ShSMCH, Dhaka.

5. Dr.Fayeem Chowdhury Sony, Junior Consultant Surgery, ShSMCH, Dhaka.

6. Dr.Amit Sen Gupta, Asstt. Registrar, department of surgery, ShSMCH, Dhaka.

7. Dr. Md. Shafiqul Islam, IMO, department of surgery, ShSMCH. Author of Correspondence: Dr. S.M Quamrul Akther, Assoc. Professor of surgery. Shaheed Suhrawardy Medical College and Hospital, Dhaka. E- mail qu_sanju@yahoo.com

\section{Case Report :}

A 25 year old female was admitted in our hospital with complaints of a lump in the epigastric region for last four years. She is having vomiting every time after taking food for last 06 months. On query, she gave history suggestive of post partum psychosis 04 years back. Examination revealed pale looking short hair woman with features of depression in appearance with visible epigastric lump. Palpation of her abdomen revealed a large, firm, mobile non tender epigastric mass. USG of whole abdomen confirmed the presence of large gastric mass with internal air loculi involving entire stomach .

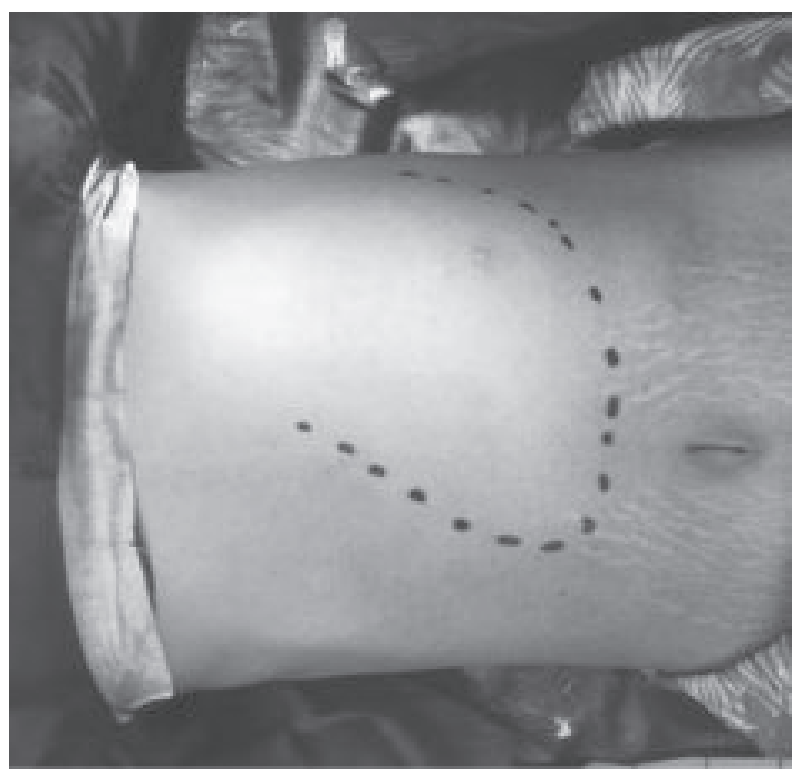

Fig.-1: Outline of Epigastric lump 
On endoscopy a trichobezoar is found almost entire capacity of stomach.
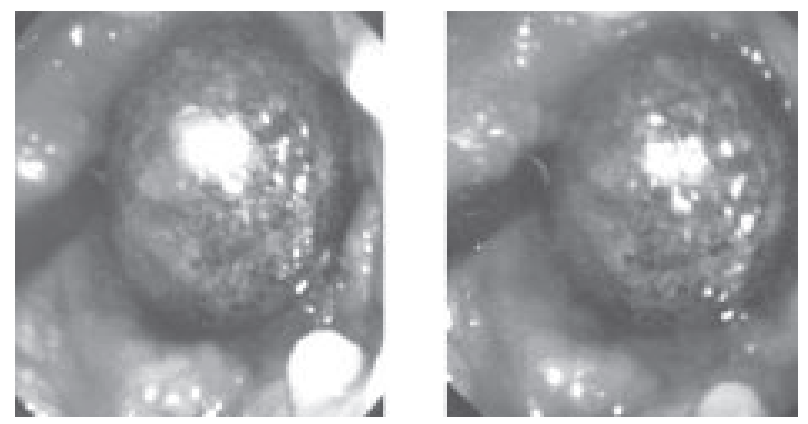

Pic 2: Endoscopic view of trichobezoar

Barium meal X ray revealed hugely distended stomach.

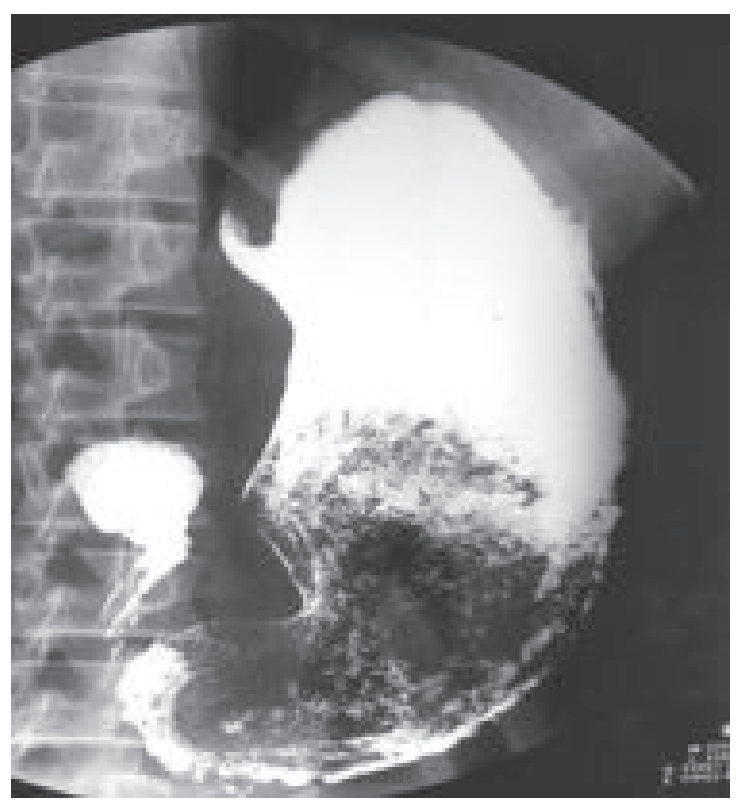

Pic 3: Barium meal view of trichobezoar

Considering site and potential for complications, operative removal of trichobezoar was taken successfully via gastrostomy. The patient was discharged from hospital on day $7^{\text {th }}$ post operative day after consultation with psychiatrist.

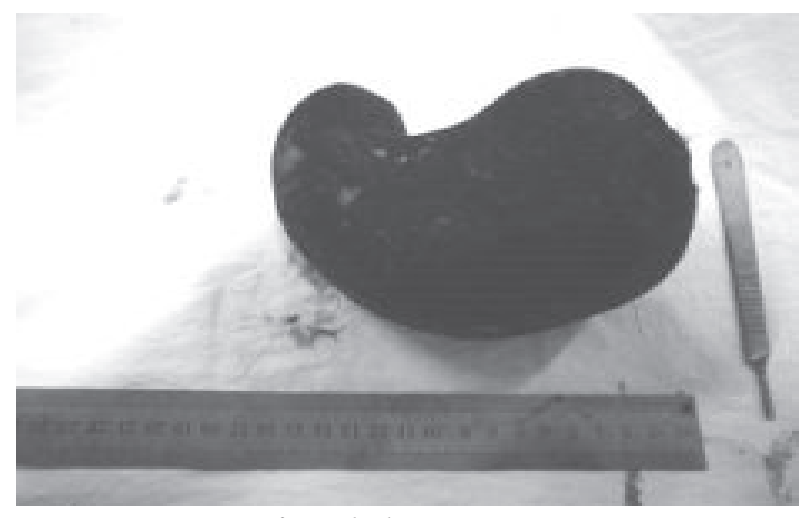

Pic 4: Specimen of trichobezoar

\section{Discussion:}

Trichobezoars commonly occur in adolescent females, often with an underlying psychiatric or social problem. Clinical presentation of these patients may be confusing as often they are not forthcoming with a history of trichophagia either due to embarrassment or the unintentional nature of the problem. Although this is a rare condition, numerous case reports and series have been reported as high mortality may follow complications associated with this condition. There is a study of common occurrence of trichobezoar in paediatric group with early complications

Trichobezoars in humans were first described from a post mortem by Swain in 1854 . The postulated reason for formation in the stomach is that hair is undigestable and due to its smooth nature cannot be propulsed with peristalsis and over time forms a bezoar within the stomach. This bezoar can extend distally from the stomach into the caecum. Extension of the bezoar from the stomach into the jejunum or further on is referred to as "Rapunzel syndrome,"5,6 first described by Vaughan Jr. et al. in $1968^{10,11}$. Rapunzel was a long haired girl in a German fairy tale by Grimm brothers. Bezoars can also be found distally in the gastrointestinal tract without continuity with the stomach bezoar due to breakage and distal propulsion. Trichobezoars continue to grow in size with continued ingestion of hair and this increases the risk of severe complications. The most common of these complications that have been reported over the years include gastric mucosal erosion ${ }^{7}$, ulceration, and perforation of the stomach or the small intestine, gastric outlet obstruction ${ }^{7}$, intussusception $^{8}$, obstructive jaundice ${ }^{9}$, protein-losing enteropathy ${ }^{10}$, pancreatitis $^{11}$ and death.

Presentation ranges from nonspecific abdominal or epigastric pain, to a range of complications as mentioned ${ }^{12}$. Clinical examination often reveals a large mobile epigastric mass that may be indentable, the so-called Lamerton's $\operatorname{sign}^{13}$. Endoscopy is usually diagnostic. The hair appears black (despite the normal hair colour) due to denaturing of the hair protein by the acid. CT scan of the whole abdomen is now being rountinely used to diagnosir bezoar. ${ }^{14,15}$ Management options include endoscopic or laparoscopic removal, or via laparotomy through opening the portion of the GI tract involved in beaoare. ${ }^{16}$

\section{Conclusion:}

Trichobezoars should be considered as a differential diagnosis in a young female patient of psychiatric disorder presenting with a mobile epigastric mass. Diagnosis can be easily made with the use of USG, endoscopy\& Barium meal X-ray. Management almost always requires surgical removal $^{9}$. Now a days it may be emphasized that the 
majority of these patients have an underlying psychiatric or social disorder. A multidisciplinary approach is essential to prevent recurrence of the problem.

\section{References:}

1. Samad A, Ahmad M, and Latif A, "Bezoars: a review and report of two cases," Journal of the College of Physicians and Surgeons Pakistan, vol. 7, no. 6, pp. 263-265, 1997

2. Khattak S and Asghar K, "Trichobezoar," Gomal Journal of Medical Sciences, vol. 2, no. 1, pp. 25-26, 2004.

3. Christenson G A and Crow S J, "The characterization and treatment of Trichotillomania," Journal of Clinical Psychiatry, vol. 57, no. 8, pp. 42-49, 1996.

4. Christenson G A, Mackenzie, and J. E. Mitchell, "Characteristics of 60 adult chronic hair pullers," American Journal of Psychiatry, vol. 148, no. 3, pp. 365-370, 1991.

5. M. E. Rabie, A. R. Arishi, A. Khan, H. Ageely, G. A. S. ElNasr, and M. Fagihi, "Rapunzel syndrome: the unsuspected culprit," World Journal of Gastroenterology, vol. 14, no. 7, pp. 1141-1143, 2008.

6. D. E. Ventura, F. A. Mardiros Herbella, S. T. Schettini, and C. Delmonte, "Rapunzel syndrome with a fatal outcome in a neglected child," Journal of Pediatric Surgery, vol. 40, no. 10, pp. 1665-1667, 2005.

7. Chisholm E M, LeongH T, Chung S C S, and Li A K C, "Phytobezoar: an uncommon cause of small bowel obstruction," Annals of the Royal College of Surgeons of England, vol. 74, no. 5, pp. 342-344, 1992
8. Mehta M H and Patel R.V, "Intussusception and intestinal perforations caused by multiple trichobezoars," Journal of Pediatric Surgery, vol. 27, no. 9, pp. 1234-1235, 1992.

9, Schreiber H and Filston H C, "Obstructive jaundice due to gastric trichobezoar," Journal of Pediatric Surgery, vol. 11, no. 1, pp. 103-104, 1976.

10. Hossenbocus A and Colin Jones D G, "Trichobezoar, gastric polyposis, protein losing enteropathy and steatorrhoea," Gut, vol. 14, no. 9, pp. 730-732, 1973.

11 Shawis R N and Doig C M, "Gastric trichobezoar associated with transient pancreatitis," Archives of Disease in Childhood, vol. 59, no. 10, pp. 994-995, 1984.

12. Jensen A R, Trankiem C T, Lebovitch S, and Grewal H, "Gastric outlet obstruction secondary to a large trichobezoar," Journal of Pediatric Surgery, vol. 40, no. 8, pp. 1364-1365, 2005.

13. Lamerton A J, "Trichobezoar: two case reports-a new physical sign," American Journal of Gastroenterology, vol. 79, no. 5, pp. 354-356, 1984.

14. Tamminen $\mathrm{J}$ and Rosenfeld D, "CT diagnosis of a gastric trichobezoar," Computerized Medical Imaging and Graphics, vol. 12, no. 6, pp. 339-341, 1988

15. Navab F and Sabol J, "Images in clinical medicine," New England Journal of Medicine, vol. 336, no. 24, p. 1721, 1997. 16. Gorter R R, Kneepkens C M F, Mattens E C J L, Aronson D C, and Heij H A, "Management of trichobezoar: case report and literature review," Pediatric Surgery International, vol. 26, no. 5, pp. 457-463, 2010 